\title{
Evaluation and management of intracranial mass lesions in AIDS
}

\section{Report of the Quality Standards Subcommittee of the American Academy of Neurology}

\begin{abstract}
Mission statement. The Quality Standards Subcommittee of the American Academy of Neurology (AAN) is charged with developing practice parameters for neurologists for diagnostic procedures, treatment modalities, and clinical disorders. The selection of topics for which practice parameters are developed is based on prevalence, frequency of use, economic impact, membership involvement, controversy, urgency, external constraints, and resources required. This paper addresses the management of intracranial masses in persons infected with the human immunodeficiency virus (HIV).
\end{abstract}

Justification. Through October 31, 1995, there were 501,310 persons with AIDS reported to the Centers for Disease Control and Prevention (CDC).1 Ten percent of these cases were reported during the period 1981 to $1987,41 \%$ during 1988 to 1992 , and 49\% during 1993 to October 31, 1995. ${ }^{1}$ In 1990, an estimated one million individuals were infected with HIV in the United States, ${ }^{2}$ and the more recent epidemiologic data on AIDS from the CDC suggest a substantial increase in that number.

Intracranial mass lesions are among the most common neurologic consequences of HIV infection. Clinically relevant neurologic disease is observed in as many as two-thirds of patients with HIV infection $^{3}$ and heralds the development of AIDS in $10 \%{ }^{4}$ to $20 \%$ of patients; intracranial mass lesions account for as many as one-half these neurologic disorders. The nature of the HIV-associated intracranial mass lesions falls into three distinct categoriesopportunistic infections, neoplasms, and cerebrovascular diseases. Toxoplasma encephalitis, the most common cause of intracranial mass lesions in AIDS, occurs in 3 to $10 \%$ of patients with AIDS in the United States and in up to $50 \%$ of patients with AIDS in Europe and Africa. ${ }^{5}$ Primary CNS lym- phoma (PCNSL), the second most common cause of AIDS-related intracranial mass lesions in the developed world, occurs in up to $2.0 \%$ of patients ${ }^{6}$ and appears to be increasing in incidence, possibly as a consequence of improved survival for the profoundly immunosuppressed..$^{67}$ Other causes of intracranial mass lesions in AIDS include tuberculous abscesses and tubereulomas, cryptococcal abscesses and cryptococcomas, Nocardia abscesses, syphilitic gummas, Candida abscesses, and other infectious disorders; metastatic tumors; and cerebrovascular disease when accompanied by edema.

The proper management of an HIV-infected patient presenting with an intracranial mass lesion requires a working knowledge of the various etiologies of intracranial mass lesions observed with HIV and their relative frequencies, clinical and radiographic manifestations, associated therapeutic options, and prognosis. There has been considerable controversy regarding the management of these lesions, particularly with respect to when to proceed to a diagnostic brain biopsy. Both quality of life and survival may be affected by the course of action. ${ }^{8-11}$ Therefore, practice parameters are suggested for the management of HIV-infected patients with intracranial mass lesions.

Description of process. To our knowledge, only one study to date has specifically addressed the issue of diagnosis and management of intracranial mass lesions with HIV infection in a comprehensive, prospective manner ${ }^{12}$; therefore, recommendations with respect to this issue have been largely based on personal experience and literature review. A Medline (National Library of Medicine) search of the relevant literature from 1981 through December 1996 was undertaken employing a strategy in which the terms "HIV-1," "acquired immunodeficiency syndrome," and "HIV infections" occurred with either "toxoplas- 
mosis," "brain," or "brain neoplasms." A total of 468 relevant papers were identified. Studies reporting a series of patients with intracranial mass lesions were included in the review. Additionally, general textbooks on neurology, infectious diseases, or AIDS were consulted.

Recommendations for the management of intracranial mass lesions were solicited from the members of the Working Group. The members of this group are experts broadly representative of the disciplines involved in the diagnosis and treatment of HIVassociated intracranial mass lesions and are regarded as experts in the field. The material available from the literature review was integrated with a consensus arrived at by a panel of experts in the discipline of the neurologic complications of AIDS. The disciplines represented by this body of experts include adult neurology (J. Berger, C. Hall, J. McArthur), pediatric neurology (M. Mintz), neurosurgery (R. Levy), radiology (M.J.D. Post), and infectious diseases (M. Pierce). Drafts of this recommendation were circulated among the members of the group until consensus was achieved.

After a consensus was achieved among the Working Group, the recommendations were circulated to other members of the AAN with a specific interest in AIDS-related neurologic complications (R. Price, D. Simpson, L. Epstein, A. Belman, T. Tucker, K. Kieburtz, B. Navia) and to specific lay groups involved with issues related to AIDS research, care, and treatment (ACT UP).

Scientific body. Background and scope of the problem. Intracranial mass lesions account for as many as one-half the neurologic disorders associated with HIV infection. Although these lesions are typically observed in patients with advanced immunosuppression, they are not infrequently the presenting manifestation of HIV infection. The spectrum of underlying etiologies of HIV-associated intracranial mass lesions is broad.

Toxoplasmosis is the most common cause of intracerebral mass lesion occurring in adults in association with HIV infection. ${ }^{13,14}$ CNS toxoplasmosis generally occurs with advanced stages of immunosuppression. ${ }^{10}$ In the United States, 10 to $40 \%$ of adults with AIDS are latently infected with Toxoplasma gondii, an obligate intracellular parasite with worldwide distribution. ${ }^{15}$ Approximately 25 to $50 \%$ of AIDS patients who are seropositive for $T$ gondii will ultimately develop toxoplasmosis encephalopathy in the absence of prophylactic therapy. In a study from San Francisco, cerebral toxoplasmosis occurred in $4.1 \%$ of all patients with AIDS and $28 \%$ of AIDS patients with neurologic disease symptoms. ${ }^{16}$ At autopsy, between $10 \%{ }^{17}$ and $30 \%{ }^{18}$ of AIDS patients have cerebral toxoplasmosis. In a combined clinicopathologic series from Miami in $1987,{ }^{3}$ it accounted for $40 \%$ of all identified neurologic illnesses. In one study, ${ }^{12}$ the probability of cerebral toxoplasmosis in the Toxoplasma-seropositive patient with
Table 1 Etiologies of mass lesions in HIV infection

\section{Opportunistic infection \\ Parasites \\ Toxoplasma gondii \\ Cysticercosis \\ Fungi \\ Cryptococcus neoformans \\ Candida albicans \\ Aspergillosis \\ Mucormycosis \\ Coccidioidomycosis \\ Bacteria \\ Mycobacterium tuberculosis \\ Nocardia \\ Listeria monocytogenes \\ Treponema pallidum

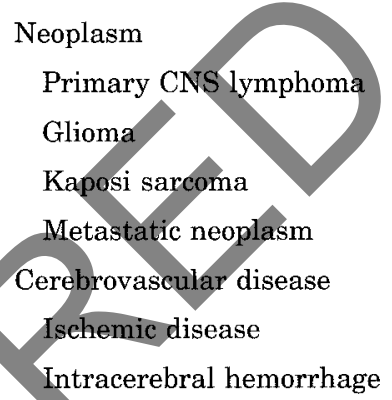

Mycobacterium avium-intracellulare

an intracranial mass lesion who had not been receiving anti-Toxoplasma prophylaxis therapy was 0.87 , but was 0.59 if anti-Toxoplasma prophylaxis had been administered. Other opportunistic infections (table) resulting in intracranial mass lesions are observed with varying frequency.

The most common brain neoplasm observed in association with HIV infection is PCNSL. As many as $0.6 \%$ of AIDS patients present with PCNSL, and PCNSL ultimately develops in up to $2.0 \% .{ }^{6}$ Antinori et al. ${ }^{12}$ found the probability of PCNSL in a Toxoplasma-seronegative patient with an intracranial mass lesion to be 0.74 . Other neoplasms that have been reported in association with HIV infection include gliomas, Kaposi's sarcoma, and metastatic tumor.

Although not invariably associated with mass effect, cerebrovascular disease when associated with edema is another potential cause of intracranial mass lesions in HIV-infected patients. The reported incidence of cerebrovascular disease in clinical studies of AIDS patients ranges from 0.5 to $7 \% .^{3,13,16,19,20}$ This incidence is even higher in autopsy studies in which estimates of stroke have varied between 11 and $34 \% .{ }^{21-24}$ The spectrum of cerebrovascular diseases that occurs in association with HIV infection is quite broad and includes both ischemic and hemorrhagic disease.$^{25}$ In general, ischemic disease is more 
common than cerebral hemorrhage, ${ }^{24,25}$ despite the frequency of concomitant thrombocytopenia. Cerebral vasculitis may also complicate HIV infection, occasionally occurring as a consequence of concomitant opportunistic infection, such as herpes zoster, ${ }^{26-29}$ syphilis, ${ }^{30}$ or other infections..$^{25}$

Clinical considerations. The presence of an intracranial mass lesion in an HIV-infected person is generally heralded by one or more of the following: headache, seizures, altered level of consciousness, impaired cognitive function, or focal neurologic signs and symptoms. Other potential etiologies for these findings in the presence of HIV infection include the following: viral meningitis or meningoencephalitis caused by HIV or by opportunistic infection with other viruses (such as cytomegalovirus); bacterial, fungal, or neoplastic meningitis without an accompanying intracerebral mass lesion;metabolic and nutritional disorders; and drug toxicity. The most sensitive diagnostic study for the demonstration of an intracranial mass lesion is cranial MRI performed with and without a contrast agent, such as gadolinium. ${ }^{31}$ However, the routine use of a contrast agent with MRI in patients with AIDS is not without controversy. ${ }^{32}$ The limited availability of the MRI scanners as well as other considerations (e.g., degradation of the image by movement, the time needed to complete the study, and the expense) may preclude its performance. CT of the head with a double dose of IV iodinated contrast (approximately 78 grams of iothalamate meglumine) via bolus and drip infusion followed 1 hour later by high-resolution CT is a very sensitive technique for detecting these lesions. ${ }^{33}$ However, its limitations, particularly with respect to the visualization of lesions in the posterior fossa, are well recognized.

Recommendations. After the presence of an intracranial lesion is confirmed by one of the above studies, a decision needs to be made for its appropriate management (figure). All recommendations are guidelines unless otherwise stated.

1. Large lesions with mass effect threatening impending herniation require open biopsy with decompression (standard). This recommendation does not apply if the patient is terminal or has an advance directive specifically requesting no intervention.

2. When available, ${ }^{201} T 1$ SPECT is an option. Although not highly sensitive, particularly with small $^{34}$ or necrotic ${ }^{35}$ lesions, thallium ${ }^{201}$ single photon emission computed tomography ( ${ }^{201} \mathrm{~T} 1$ SPECT), when positive, appears to be highly specific for PCNSL. ${ }^{34-36} \mathrm{~A}$ positive result warrants stereotactic brain biopsy. Similar results have been obtained with PET employing ${ }^{18} \mathrm{~F}$ fluorodeoxyglucose (18 FDG-PET). ${ }^{37-38}$

3. Empiric treatment for toxoplasmosis should be instituted in all other cases, except when a single intracranial mass lesion accompanies negative serology for toxoplasmosis. Neither factor (single lesion or negative serology) alone ap-

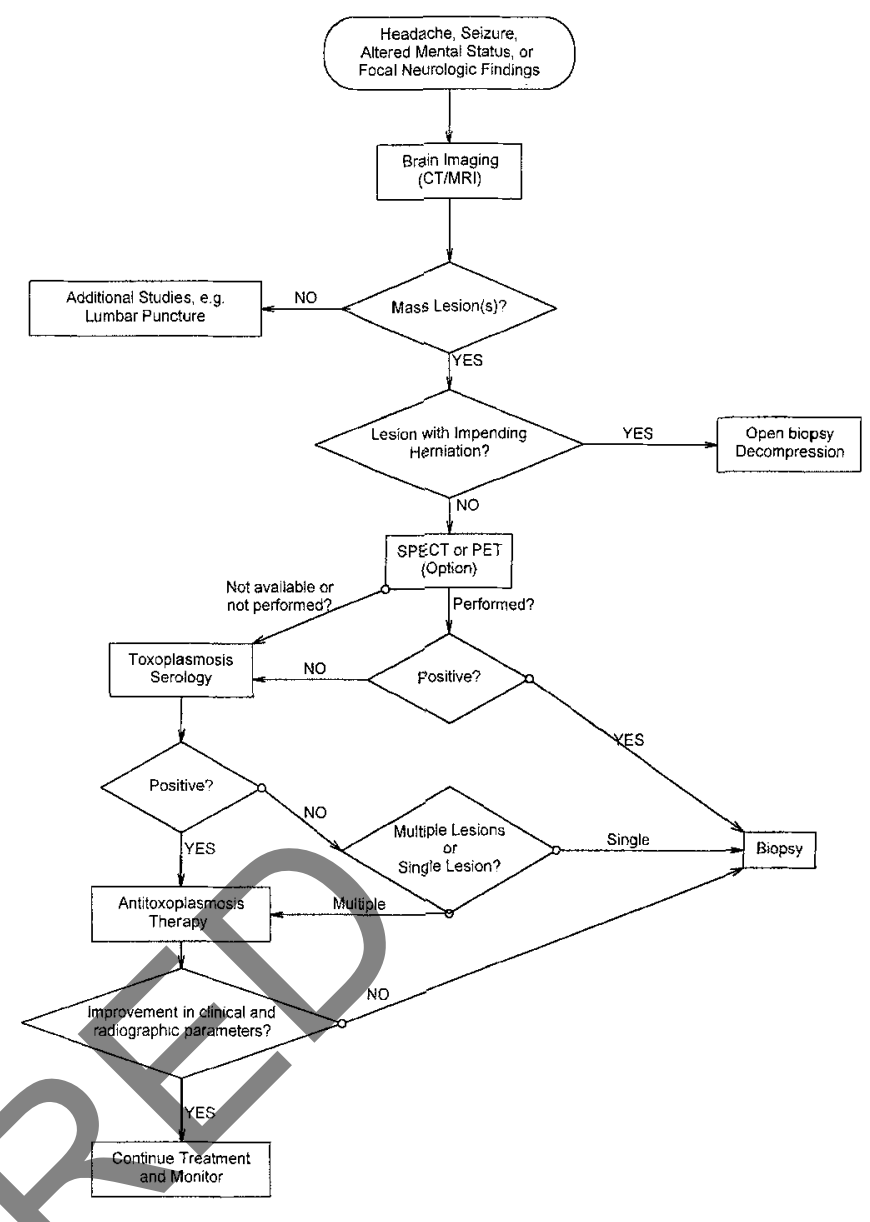

Figure. Algorithm for the evaluation and treatment of intracranial mass lesions in AIDS patients.

pears to have sufficient negative predictive value for CNS toxoplasmosis to justify stereotactic brain biopsy.

4. The therapy of toxoplasma encephalitis is oral pyrimethamine (an initial loading dose of 50 to $200 \mathrm{mg}$ followed by 25 to $50 \mathrm{mg} / \mathrm{d}$ ) and 6 to 8 grams of sulfadiazine per day divided into four equal doses. Individuals allergic to sulfadiazine may be desensitized to sulfadiazine or alternatively treated with clindamycin $2,400 \mathrm{mg}$ per day in three equal doses. ${ }^{39,40}$ Other treatment alternatives include atovaquone or azithromycin. In children, pyrimethamine $2 \mathrm{mg} / \mathrm{kg} / \mathrm{d}$ is administered in divided doses every 12 hours for 1 to 3 days than as $1 \mathrm{mg} / \mathrm{kg}$ daily or as divided doses every 12 hours to a maximum of $25 \mathrm{mg}$ per day. It is administered in conjunction with sulfadiazine $120 \mathrm{mg} / \mathrm{kg} / \mathrm{d}$ in divided doses every 6 hours in doses not to exceed the adult dose. Both drugs cross the blood-brain barrier. ${ }^{41}$ Folinic acid, 5 to $10 \mathrm{mg} / \mathrm{d}$, is needed to diminish bone marrow suppression. Treatment with corticosteroids should be avoided unless brain herniation is threatened. An apparent response to antitoxoplasmosis therapy in the face of concomitant administration of corticosteroids 
should be interpreted cautiously, and careful reevaluation after discontinuation is required.

5. The concomitance of negative toxoplasmosis serology and a single lesion on radiographic imaging is deemed sufficient to warrant the performance of a stereotactic biopsy. Although single lesions visualized by radiographic imaging were believed rare with toxoplasmosis, ${ }^{42,43}$ in one large study, ${ }^{10} 28$ of 103 patients with toxoplasmosis $(27 \%)$ had single lesions on CT, and 3 of $21(14 \%)$ had single lesions on MRI. Another study revealed that $17 \%$ of single lesions were toxoplasmosis, ${ }^{43}$ although single lesions were more than four times as likely to be lymphoma as toxoplasmosis. ${ }^{44}$ Additionally, serology for toxoplasmosis has been reported to be negative in the presence of established CNS toxoplasmosis. In one study, 13 of 80 patients with clinical toxoplasmosis $(16 \%)$ and 4 of 18 with pathologically proven toxoplasmosis $(22 \%)$ had undetectable plasma anti-Toxoplasma IgG antibody titers by indirect immunofluorescence assay. ${ }^{10}$ Among the explanations for falsenegative antibody titers for toxoplasmosis are recently acquired infection and insensitive assays. ${ }^{10}$ The issue of whether CNS toxoplasmosis may occur in the setting of negative antitoxoplasmosis antibody titers in a sensitive and reliable assay remains controversial. Some investigators contend that a negative toxoplas mosis serology is sufficiently predictive to exclude the diagnosis of cerebral toxoplasmosis. However, the combination of a negative toxoplasmosis serology and a single lesion on radio graphic imaging strongly militates against the presence of Toxoplasma encephalitis

6. Patients treated presumptively for toxoplasmosis need to be carefully monitored both clinically and radiographically for response to treatment over the succeeding 10- to 14-day period. ${ }^{45}$ In a large clinical series of patients with Toxoplasma encephalitis, $74 \%$ had improvement by day 7 of therapy and $91 \%$ by day $14 .{ }^{45}$ The median time to a response was 5 days. ${ }^{45}$ Failure to respond to therapy, indicated by persistence or worsening of either clinical symptomatology or the mass lesions observed on radiographic imaging (MRI or CT) dictates the performance of a diagnostic stereotactic biopsy. If clinical and radiographic assessments indicate a response, antitoxoplasmosis therapy should be continued indefinitely with follow-up radiographic imaging performed every 4 to 6 weeks until the lesions have regressed in their entirety or demonstrate no further change. Apparent clinical improvement should be interpreted cautiously in the evaluation of a seemingly therapeutic response to antitoxoplasmosis therapy if corticosteroids have also been administered. Reevaluation on continued antibiotic therapy in the absence of corticosteroid therapy is mandated within 2 weeks.

7. In HIV-infected children, proceeding directly to stereotactic biopsy may be a consideration to eliminate diagnoses other than opportunistic infections. In contrast to adults, opportunistic infections of the CNS, including toxoplasmosis, are rarely observed in children. ${ }^{46}$ Although toxoplasmosis in HIV-infected children has been anecdotally reported, ${ }^{47}$ it was not observed in two separate cohorts examined for HIVassociated neurologic disease. ${ }^{48,49}$

Risk assessment and costs. The risks of CT are chiefly those inherent to radiograph exposure and those associated with the contrast agent-allergic reactions, nephrotoxicity, encephalopathy, etc. CT in pregnant women is relatively contraindicated. MRI is a benign procedure, but is contraindicated in persons with pacemakers and metallic implants. Because of the lengthier amount of time required to complete an MRI and the sequestration of the patient in a confined tube often generating feelings of claustrophobia, the MRI is perceived as more inconvenient than the $\mathrm{CT}$. The risks of stereotactic brain biopsy include the risks of anesthesia, intracranial hemorrhage, and infection. The expense of this procedure with hospital costs averages approximately $\$ 10,000$.

The risk of radionuclide brain scanning is chiefly the allergic reaction to the isotope preparation. The cost of the study is approximately $\$ 1,000$. Although experience with ${ }^{18} \mathrm{FDG}-\mathrm{PET}$ is increasing, its expense and limited availability greatly restrict its general application to the evaluation of intracranial mass lesions in AIDS.

In a population of 500 non-HIV-infected individuals, brain biopsy was associated with a $0.2 \%$ mortality and a $1.0 \%$ morbidity rate chiefly due to intracranial hemorrhage. ${ }^{50}$ However, the risk associated with brain biopsy in AIDS patients may be higher. Levy et al. ${ }^{51}$ observed intracranial hemorrhage in 4 of 50 AIDS patients (8\%) undergoing brain biopsy. Antinori et al., ${ }^{12}$ in their series of 136 patients, reported a morbidity of $12 \%$ and mortality of $2 \%$. Additionally, the published rate of nondiagnostic brain biopsies in AIDS patients has varied from 4 to $36 \% .^{12,51,52}$ Although some studies have employed CSF polymerase chain reaction for EpsteinBarr virus and toxoplasmosis ${ }^{12}$ in their decision analysis, in general, lumbar puncture is not recommended in persons with intracranial mass lesions because of the risk of brain herniation.

Recommendations for the next review. As experience with the neurologic complications of HIV infection grows and as treatment options improve, these recommendations may become outdated. For instance, a high predictive value for the presence of neoplasm by radionuclide brain scanning may suggest empirical radiation therapy and obviate the need for brain biopsy. Similarly, the demonstration 
of a uniformly high specificity of toxoplasmosis serology may alter the algorithm and suggest earlier brain biopsy without a trial of antitoxoplasmosis therapy.

Definitions for classification of evidence:

Class I. Evidence provided by one or more welldesigned randomized controlled clinical trials, including overviews (meta-analyses) of such trials.

Class II. Evidence provided by well-designed observational studies with concurrent controls (e.g., case control and cohort studies).

Class III. Evidence provided by expert opinion, case series, case reports, and studies with historical controls.

\section{Definitions for strength of recommendations:}

Standards. A principle for patient management that reflects a high degree of clinical certainty (usually this requires Class I evidence that directly addresses the clinical question or overwhelming Class II evidence when circumstances preclude randomized clinical trials).

Guidelines. A recommendation for patient management that reflects moderate clinical certainty (usually this requires Class II evidence or a strong consensus of Class III evidence).

Practice option. A strategy for patient management for which the clinical utility is uncertain (inconclusive or conflicting evidence or opinion).

Practice advisory. A practice recommendation for emerging and/or newly approved therapies or technologies based on evidence from at least one class I study. The evidence may demonstrate only a modest statistical effect or limited (partial) clinical response, or significant cost-benefit questions may exist. Substantial (or potential) disagreement among practitioners or between payers and practitioners may exist.

\section{Acknowledgments}

The Quality Standards Subcommittee (QSS) thanks the following individuals for providing expert input into the development of this practice parameter: Joseph R. Berger, MD, FACP; Judith Donovan Post, MD; Mark Mintz, MD; Mark A. Pierce, MD; Justin C. McArthur, MB, BS, MPH; Colin D. Hall, MBChB. The subcommittee would also like to acknowledge QSS member Michael K. Greenberg, MD, for his effort in facilitating the development of this parameter.

Quality Standards Subcommittee Members: Michael K. Greenberg, MD, Chair; Milton Alter, MD, PhD; Stephen Ashwal, MD; John Calverley, MD; Robert G. Miller, MD; Gary Franklin, MD, MPH; Jacqueline French, MD; Douglas J. Lanska, MD; Shrikant Mishra, MD, MBA; Germaine L. Odenheimer, MD; Jay H. Rosenberg, MD; Catherine A. Zahn, MD; James Stevens, MD; Jasper Daube, MD; Benjamin Frishberg, MD; George Paulson, MD; Richard Pearl, MD; Cathy Sila, MD.

Note. This statement is provided as an educational service of the American Academy of Neurology (AAN). It is based on an assessment of current scientific and clinical information. It is not intended to include all possible proper methods of care for a particular neurologic problem or all legitimate criteria for choosing to use a specific procedure. Neither is it intended to exclude any reasonable alternative methodologies. The AAN recognizes that specific patient care decisions are the prerogative of the patient and the physician caring for the patient based on all of the circumstances involved.

\section{References}

1. Centers for Disease Control. First 500,000 AIDS casesUnited States, 1995. MMWR Morb Mortal Wkly Rep 1995;44: 849-853.

2. Centers for Disease Control. HIV prevalence estimates and AIDS case projections for the United States: report based upon a workshop. MMWR Morb Mortal Wkly Rep 1990;39(RR16): $1-31$.

3. Berger JR, Moskowitz L, Fischl M, Kelley RE. Neurologic disease as the presenting manifestation of acquired immunodeficiency syndrome. South Med J 1987;80:683-686.

4. Bredesen DE, Messing R. Neurological syndromes heralding the acquired immunodeficiency [abstract]. Neurology 1983;14: 141.

5. Luft BJ, Remington JS. Toxoplasmic encephalitis. Clin Infect Dis 1992;15:211-222.

6. Levy RM, Janssen RS, Bush TJ, et al. Neuroepidemiology of acquired immunodeficiency syndrome. In: Rosenblum ML, Levy RM, Bredesen DE, eds. AIDS and the nervous system. New York: Raven Press, 1988:13-27.

7. Remick SC, Diamond C, Migliozzi JA, et al. Primary central nervous system lymphoma in patients with and without the acquired immune deficiency syndrome. Medicine 1990;69:345360 .

8. Renold C, Sugar A, Chave P, et al. Toxoplasma encephalitis in patients with the acquired immunodeficiency syndrome. Medicine 1992,71:224-239.

9. Zimmer C, Marzheurser S, Patt S, et al. Stereotactic brain biopsy in AIDS. J Neurol 1992;239:394-400.

10. Porter SB, Sande MA. Toxoplasmosis of the central nervous system in the acquired immunodeficiency syndrome. N Engl J Med 1992;327:1643-1648.

1. Rosenblum ML, Levy RM, Bredesen DE, So YT, Wara W, Ziegler JL. Primary CNS lymphomas in patients with AIDS. Ann Neurol 1988;23:S13-S16.

12. Antinori A, Ammassari A, De Luca A, et al. Diagnosis of AIDS-related focal brain lesions: a decision-making analysis based on clinical and neuroradiologic characteristics combined with polymerase chain reaction assays in CSF. Neurology 1997;48:687-694.

13. McArthur JC. Neurologic manifestations of AIDS. Medicine 1987;66:407-437.

14. Wanke C, Tuazon CU, Kovacs A, et al. Toxoplasma encephalitis in patients with acquired immunodeficiency syndrome: diagnosis and response to therapy. Am J Trop Med Hyg 1987; 36:509-516.

15. Luft BJ, Remington JS. Toxoplasmic encephalitis. J Infect Dis 1988;157:1-6.

16. Levy RM, Bredesen DE, Rosenblum ML. Neurological manifestations of the acquired immunodeficiency syndrome (AIDS): experience at UCSF and review of the literature. J Neurosurg 1985;62:475-495.

17. Petito CK, Cho ES, Lemann W, et al. Neuropathology of acquired immunodeficiency syndrome (AIDS): an autopsy review. J Neuropathol Exp Neurol 1986;45:635-646.

18. Moskowitz LB, Hensley GT, Chan JC, et al. The neuropathology of acquired immunodeficiency syndrome. Arch Pathol Lab Med 1984;108:867-872.

19. Jordan BD, Navia BA, Petito C, et al. Neurological syndromes complicating AIDS. Front Radiat Ther Oncol 1985;19:82-87.

20. Engstrom J, Lowenstein DH, Bredesen DE. Cerebral infarctions and transient neurological deficits associated with AIDS. Neurology 1988;38(suppl 1):241.

21. Anders KH, Guerra W, Tomiyasu U, et al. The neuropathology of AIDS: UCLA experience and review. Am J Pathol 1986; 124:537-558.

22. Vinters HV, Tomiyasu U, Anders KH. Neuropathologic complications of infection with the human immunodeficiency virus (HIV). Prog AIDS Pathol 1989;1:101-130.

23. Sharer LP, Kapila R. Neuropathologic observations in acquired immune deficiency syndrome. Acta Neuropathol (Berl) 1985;66:188-198.

24. Mizusawa H, Hirano A, Llena JF, Shintaku M. Cerebrovascu- 
lar lesions in acquired immune deficiency syndrome (AIDS). Acta Neuropathol (Berl) 1988;76:451-457.

25. Berger JR, Harris JO, Gregorios J, Norenberg M, Cerebrovascular disease in AIDS: a case control study. AIDS 1990;4:239244.

26. Van de Perre P, Bakkers E, Batungwanayo J, et al. Herpes zoster in African patients: an early manifestation of HIV infection. Scand J Infect Dis 1988;20:277-282.

27. Zaraspe-Yoo E, Miletich R, Tourtellotte WW. Herpes zoster ophthalmicus with contralateral hemiplegia in a patient with autoimmune deficiency syndrome (AIDS) [abstract]. Neurology 1984;34(suppl 1):229

28. Eidelberg D, Sotrel A, Houtoupian S, Neumann PE, Pumarola-Sune T, Price RW. Thrombotic cerebral vasculopathy associated with herpes zoster. Ann Neurol 1986;19:7-14.

29. Morgello S, Block GA, Price RW, Petito CK. Varicella-zoster virus leukoencephalitis and cerebral vasculopathy. Arch Pathol Lab Med 1988;112:173-177.

30. Katz D, Berger JR. Neurosyphilis in AIDS. Arch Neurol 1989; 46:895-901.

31. Post MJD, Sheldon JJ, Hensley GT, et al. Central nervous system disease in acquired immunodeficiency syndrome: prospective correlation using $\mathrm{CT}, \mathrm{MR}$ imaging and pathologic studies. Radiology 1986;158:141-148.

32. Jensen MC, Brant-Zawadski M. MR imaging of the brain in patients with AIDS: value of routine use of IV gadopentetate dimeglumine. AJR Am J Roentgenol 1993;160:153-157.

33. Post MJD, Kursunoglu SJ, Hensley GT, et al. Cranial CT in acquired immunodeficiency syndrome: spectrum of diseases and optimal contrast enhancement technique. AJNR Am J Neuroradiol 1985;6:743-754

34. Ruiz A, Ganz WI, Post MJD, Camp A, Landy H, Mallin W. Use of thallium ${ }^{201}$ brain SPECT to differentiate cerebral lymphoma from Toxoplasma encephalitis in AIDS patients. AJNR Am J Neuroradiol 1994;15:1885-1894.

35. Berry I, Gaillard JF, Guo Z, et al. Cerebral lesions in AIDS. What can be expected from scintigraphy? Cerebral tomographic scintigraphy using thallium-201: a contribution to the differential diagnosis of lymphomas and infectious lesions. J Neuroradiol 1995;22:218-228.

36. O'Malley JP, Ziessman HA, Kumar PN, et al. Diagnosis of intracranial lymphoma in patients with AIDS: value of 201 TL single-photon emission computed tomography. AJR Am J Roentgenol 1994;163:417-421.

37. Hoffman JM, Waskin HA, Schifter T, et al. FDG-PET in differentiating lymphoma from nonmalignant central nervous system lesions in patients with AIDS. J Nucl Med 1993;34: $567-575$.
38. Pierce MA, Johnson MD, Maciunas RJ, et al. Evaluating contrast-enhancing brain lesions in patients with AIDS by using positron emission tomography. Ann Intern Med 1995; 123:594-598.

39. Katlama C. Evaluation of the efficacy and safety of clindamycin plus pyrimethamine for induction and maintenance therapy of toxoplasmic encephalitis for AIDS. Eur J Clin Microbiol Infect Dis 1991;10:189-191.

40. Foppa CV, Bini T, Gregis G, Lazzarin A, Esposito R, Moroni M. A retrospective study of primary and maintenance therapy of toxoplasmic encephalitis with oral clindamycin and pyrimethamine. Eur J Clin Microbiol Infect Dis 1991;10:187189.

41. Ruskin J, Remington JS. Toxoplasmosis in the compromised host. Ann Intern Med 1976;84:193-199.

42. Levy RM, Mills CM, Pasic JP, et al. The efficacy and clinical impact of brain imaging in neurologically symptomatic AIDS patients: a prospective CT/MRI study. J AIDS 1990;3:461471

43. Ciricillo SF, Rosenblum ML. Imaging of solitary lesions in AIDS [letter]. J Neurosurg 1991;74:1029.

44. Ciricillo SF, Rosenblum ML. Use of CT and MR imaging to distinguish intracranial lesions and to define the need for biopsy in AIDS patients. J Neurosurg 1990;73:720-724.

45. Luft BJ, Hafner R, Korzun AH, et al. Toxoplasmic encephalitis in patients with the acquired immunodeficiency syndrome. N Engl J Med 1993;329:995-1000.

46. Keohane C, Gray F. Central nervous system pathology in children with AIDS. Ir J Med Sci 1991;160:277-281.

47. Biggemann B, Voit T, Neuen E, et al. Neurological manifestations in three German children with AIDS. Neuropediatrics 1987;18:99-106.

48. Roy S, Geoffroy G, Lapointe N, Michaud J. Neurological findings in HIV-infected children: a review of 49 cases. Can Neurol Sci 1992;19:453-457.

49. Belman AL, Diamond G, Dickson D, et al. Pediatric acquired immunodeficiency syndrome: neurologic syndromes. AJDC 1988;142:29-35.

50. Appuzzo MIJ, Chandrasoma P, Cohen D, Zee CH, Zelman V. Computed imaging stereotaxy: experience and perspective relative to 500 procedures applied to brain masses. Neurosurgery 1987;20:930-937.

51. Levy RM, Russel E, Yungbluth M, Frais Hidvegi D, Brody BA Dal Canto MC. The efficacy of image-guided stereotactic brain biopsy in neurologically symptomatic acquired immunodeficiency syndrome. Neurology 1992;30:186-190.

52. Vinters HV, Anders KH. Neuropathology of AIDS. Boca Raton, FL: CRC Press, 1990. 


\section{Neurology}

\section{Evaluation and management of intracranial mass lesions in AIDS [RETIRED]}

Quality Standards Subcommittee of the American Academy of Neurology

Neurology 1998;50;21-26

DOI 10.1212/WNL.50.1.21

\section{This information is current as of January 1, 1998}

\section{Updated Information \&}

Services

Citations

Permissions \& Licensing

Reprints including high resolution figures, can be found at:

http://n.neurology.org/content/50/1/21.full

This article has been cited by 5 HighWire-hosted articles: http://n.neurology.org/content/50/1/21.full\#\#otherarticles

Information about reproducing this article in parts (figures,tables) or in its entirety can be found online at:

http://www.neurology.org/about/about_the_journal\#permissions

Information about ordering reprints can be found online:

http://n.neurology.org/subscribers/advertise

Neurology ${ }^{\circledR}$ is the official journal of the American Academy of Neurology. Published continuously since 1951, it is now a weekly with 48 issues per year. Copyright. All rights reserved. Print ISSN: 0028-3878. Online ISSN: $1526-632 \mathrm{X}$.

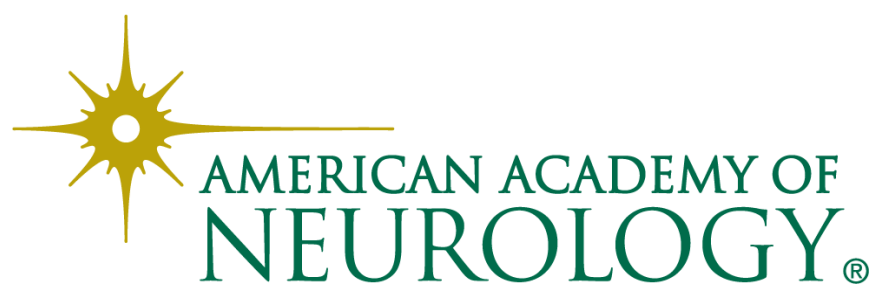

